\title{
Number of Transactions, Trade Size and the Volume-Volatility Relationship: An Interday and Intraday Analysis on the Tunisian Stock Market
}

\author{
Fethi Belhaj ${ }^{1}$, Ezzeddine Abaoub $^{2}$ \& Mohamed Naceur Mahjoubi ${ }^{3}$ \\ ${ }^{1}$ Faculty of Economics and Management Sciences of Nabeul, Tunis Carthage University, Tunisia \\ ${ }^{2}$ College of Administrative and Financial Studies, Taif University, Kingdom of Saudi Arabia \\ ${ }^{3}$ High Institute of Accounting and Business Administration, Mannouba University, Tunisia \\ Correspondence: Fethi Belhaj, Faculty of Economics and Management Sciences of Nabeul, Tunis Carthage \\ University, Tunisia. E-mail: Fethipremier@yahoo.fr
}

Received: April 11, 2015

Accepted: May 4, 2015

Online Published: May 25, 2015

doi:10.5539/ibr.v8n6p135

URL: http://dx.doi.org/10.5539/ibr.v8n6p135

\begin{abstract}
The purpose of this paper is to study the relationship between trading volume and unconditional price volatility on the Tunisian Stock Market in order to provide an empirical support to either the hypothesis of the strategic asymmetric information models or the hypothesis of competitive asymmetric information Models. More specifically, it aims to test the volume-volatility relationship and identify the component of trading volume (number of transactions or trade size) that explains more price volatility and drives this relationship. Our empirical tests are based on daily and intraday data related to the 43 most active and dynamic listed stocks on the Tunisian Stock Market from 02 January 2008 to 29 June 2012 for the daily analysis and from 03 October 2011 to 28 September 2012 for the intraday data. Our empirical analysis reveals several results. First, we confirm the strong positive contemporaneous relationship between trading volume and unconditional price volatility similarly to the Mixture of Distribution Hypothesis (MDH). Second, we show that whatever the frequency of used data, daily or intraday, the number of transactions is much more significant than the trade size in the explanation of the volatility and seems to be the dominant factor that drives the positive volume-volatility relationship. Third, we find that trade size has no explanatory power of the volatility beyond that the number of transactions and the positivity of the volume-volatility relationship reflects simply the positive relationship between number of transactions and volatility. Overall, our empirical results support the hypothesis of the strategic models and challenge the hypothesis of competitive models.
\end{abstract}

Keywords: trading volume, unconditional volatility, number of transactions, trade size, volme-volatility relationship, information flow, mixture of distribution hypothesis, competitive asymmetric information models, strategic asymmetric information models

\section{Introduction}

The volume-volatility relationship has been the subject of several financial studies during the past three decades. A large number of theses studies have documented a positive contemporaneous relationship between trading volume and price or return volatility. Karpoff (1987) cites several reasons explaining the importance of this relationship. First, the theory of the volume-volatility relationship provides insight into the structure of financial markets. Second, volume-volatility relationship has important implications for event studies that use a combination of price and volume data to draw inferences. Third, this relationship has important implications for the empirical distribution of speculative prices.

Various theories have been developed to explain the volume-volatility relationship including the mixture of distribution hypothesis Clark (1973), Epps and Epps (1976), Tauchen and Pitts (1983), Lamoureux and Lastrapes (1990), Andersen (1996), Bollerslev and Jubinski (1999), the sequential information arrival hypothesis (Copeland, 1976; Morse, 1980; Jennings, Starks, \& Fellingham, 1981; Jennings \& Barry, 1983; Darrat, Rahman, $\&$ Zhong, 2003), the differences of opinion hypothesis (Harris \& Raviv, 1993; Shale, 1993), and the asymmetric information hypothesis (Kyle, 1985; Admati \& Pfleiderer, 1988; Holthausen \& Verrecchia, 1990; Foster \& Viswanathan, 1996; Chordia \& Subrahmanyam, 2004). All these theories predict a positive relationship between 
price volatility and trading volume.

Developed by Clark (1973), Epps and Epps (1976), Tauchen and Pitts (1983), Lamoureux and Lastrapes (1990), Andersen (1996), Bollerslev and Jubinski (1999), the mixture of distribution hypothesis (MDH) remains always at the basis of all researches that address the relationship between trading volume and price or return volatility. This hypothesis assumes that volatility is highly influenced by information arrival whose trading volume is a proxy, and predicts the existence of a positive contemporaneous relationship between volume and volatility mainly due to their joint dependence on a common underlying directing variable (mixing variable) that measures the rate of information flow to the market. According to this hypothesis, the new information dissemination is contemporaneous and therefore, the instant reaction of the various actors on his arrival on the market implies a positive contemporaneous volume-volatility relationship. Empirically, this intuition leads to our first hypothesis:

H1. Trading volume and price volatility are positively and contemporaneously related due to their joint dependence to information flow whose dissemination on the market is contemporaneous and the reaction of various actors on his arrival is instantaneous.

Empirically a large number of empirical studies have documented a strong positive contemporaneous relationship between return volatility and trading volume (Jones, Kaul, \& Lipson, 1994; Lee \& Rui, 2002; Huang \& Masulis, 2003; Alsubaie \& Najand, 2009; Mahajan \& Singh, 2009; Kumar, Singh, \& Pandey, 2009; Giot, Laurent, \& Petitjean, 2010; Kao \& Fung, 2012; Chuang, Liu, \& Susmel, 2012; Huang \& Wang, 2012; Celik, 2013; Davidsson, 2014; Shahzed et al., 2014; ...). However, despite the diversity of these studies, there was no general consensus regarding the component of trading volume that best explains price volatility and drives, therefore, the positive contemporaneous volatility-volume relationship. Indeed, trading volume measured during a given period can be decomposed in number of transactions and trade size (Note 1). Thus, it would be interesting to test whether the volume-volatility relationship is driven by either one or both components. The asymmetric information hypothesis has focused on this issue. The previous literature related to this relationship distinguishes two groups of asymmetric information models: competitive asymmetric information models and strategic asymmetric information models.

The strategic asymmetric information models (Kyle, 1985; Admati \& Pfleiderer, 1988; Foster \& Viswanathan, 1996; Chordia \& Subrahmanyam, 2004; Cho, 2007) assume that the positive volume-volatility relationship mainly reflects the positive relationship between the number of transactions and volatility since informed investors tend to camouflage their trades by fragmenting them into several small and medium-sized transactions in order to conceal their identity as informed investors and thus benefit from their private information, which makes the number of transaction more informative than the traded volume. Empirically this assumption leads to our second hypothesis:

H2. Informed Tunisian investors prefer a strategic camouflage behavior through fragmenting their trading activities in several smaller transactions without revealing their information advantages in order to benefit from it.

Unlike strategic models, the competitive asymmetric information models (Easley \& O'Hara, 1987; Holthausen \& Verrecchia, 1990; Back \& Baruch, 2007; Ozsoylev \& Takayama, 2010; ...) suppose that informed investors prefer to trade large amounts of shares to enjoy their private information which could provide an important information content to the trade size and therefore leads to a significantly positive relationship between this trading variable and price volatility. Empirically this intuition leads to our third hypothesis:

H3. Informed Tunisian investors prefer to trade large amounts of shares to benefit from their private information.

Despite the massive literature on the volatility-volume relationship, few researches have emphasized the study of the relative contributions of the number of transactions and the trade size in explaining its origin. Jones, Kaul and Lipson (1994) were the first to study the relative impacts of the number of transactions and trade size on price volatility based on daily data related to a sample of listed shares on the NASDAQ from 1986 to 1991. They show that the number of transactions is much more significant than the trade size when explaining price volatility and seems to be the dominant variable leading the volume-volatility relationship, and that trade size does not provide additional information content beyond the number of transactions. These results lead Jones, Kaul and Lipson (1994) to conclude that the positivity of the volume-volatility relationship simply reflects the positive relationship between volatility and the number of transactions. Similar results were found by Jiang and Kryzanowiski (1998), Gopinath and Krishnamurti (2001) who assume that the number of transaction is strongly associated with the information flow and therefore positively related to price change.

Using daily data related to a sample of listed shares on NYSE and NASDAQ, Chan and Fong (2000) analyze 
how price volatility could be explained by both the number of transactions and trade size. They assume that the finding of Jones, Kaul and Lipson (1994) concerning trade size neutrality in the volume-volatility relationship is somewhat questionable. Indeed, if informed investors prefer to fragment their trade to hide their privileged identities, they should issue several medium sized transactions (Barclay \& Warner, 1993) and therefore, transactions will have a greater impact on prices for medium sized trade than other size categories. In order to detect the impact of the number of transactions and trade size on price volatility, Chan and Fong (2000) use a strategy similar to the one used by Jones, Kaul and Lipson (1994). The results show that in addition to the number of transactions, trade size plays a significant role in the volume-volatility relationship with a relative importance of the number of transactions in the generation of this relationship.

Chan and Fong (2006) review the relative impacts of the number of transactions and trade size on returns volatility. Unlike previous studies that measured daily volatility with the absolute value of daily returns, the authors assume that this measure is a very noisy estimator of the real latent volatility since it is calculated using only both of the opening and closing prices that could generate a very low level of volatility if they are too close, even though during the day there had been important and significant fluctuations of the intraday prices. Therefore, according to Andersen et al. (2001), they propose an estimation of the daily volatility through realized volatility obtained from summing the squares of the intraday returns associated with five-minute time intervals. Applying their empirical methodology to 30 shares composing the "Dow Jones" stock index, running from January 1993 to June 2000, Chan and Fong (2006) show that the number of transactions explains daily returns volatility better than the trade size. Specifically, they find that the number of transactions explains in average $42 \%$ of the realized daily volatility, while the trade size explains only $25 \%$. They conclude that the number of transactions appears to be the dominant variable that drives the volume-volatility relationship and that, despite its significant impact on returns volatility; the trade size does not provide a stronger explanation of price variation than that of the number of transactions.

Huang and Masulis (2003) empirically study the volume-volatility relationship on the London Stock Exchange (LSE) through decomposing volume in number of transactions and trade size. This analyze is primarily based on daily data and then on intraday data related to 100 shares composing the "FTSE-100" stock index in 1995. Considering the daily frequency of data, they show that only the number of transactions significantly affects volatility and leads the positive volume-volatility relationship. However, when trades are decomposed in size categories, the number of transactions in the small size category and the average trade size are both positively correlated with price volatility. Huang and Masulis (2003) also find that intraday data reinforce the explanatory power of the average trade size stating that small sized one has greater impact on price volatility than the other trading categories.

Giot, Laurent and Petitjean (2010) suggest a new approach to study the relative importance of the number of transactions, trade size and the order imbalance in the volume-volatility relationship through decomposing the realized volatility in two major components: a continuously varying component and a discontinuous jump component. The application of this approach to 100 listed shares on the NYSE during the period from January 1999 to September 2003, shows that the three mentioned above variables are positively related only to the continuous and persistent component of volatility, and that the number of transactions remains the dominant factor generating the positive volume-volatility relationship. Beyond the number of transactions, neither the trade size nor the order imbalance confers an explanatory power of price change regardless to the considered component of volatility.

Similarly to Giot et al. (2010), Shahzed, Duong, Kalev, and Singh (2014) empirically analyze the relative contributions of the number of transactions, the average trade size and order imbalance to the explanation of the volume-volatility relationship on the Australian financial market during 2006-2010 through decomposing volatility into a continuously varying component and a discontinuous jump component. They show that the number of transactions appears to be the dominant variable in the explanation of the volatility in comparison with trade size and order imbalance. The positive volume-volatility relationship is mainly driven by the number of transactions and the continuous component of volatility. In contrast, the average trade size, order imbalance and discontinuous jump component of volatility only play marginal and minor role in the explanation of the positivity of the volume-volatility relationship.

Our paper is related to the empirical works mentioned above. It aims to empirically investigate the contemporaneous volume-volatility relationship and to test whether the number of transactions or the trade size drives this relationship on the Tunisian stock market. Its main purpose is therefore to test whether the volume-volatility relationship in the Tunisian stock market supports the competitive asymmetric information models or the strategic asymmetric information models. 
Although there are many empirical studies on the volume-volatility relationship, there is no general consensus about the component of trading volume, number of transactions or trade size, that best explains the price volatility and drives the relationship. Moreover, most of the previous studies on this topic have focused on developed markets such as the U.S. market and it is unclear whether we can generalize its results to emerging markets. We attempt to partially fill this gap by investigating volume-volatility relationship in one of the emerging stock markets, namely the Tunisian stock market. Our empirical tests are applied on daily and intraday data related to a sample of 43 individual Tunisian stocks running from January 2, 2008 to June 29, 2012 for the daily analysis and from 03 October 2011 to 28 September 2012 for the intraday analysis.

Our results confirm the strong positive relationship between trading volume and return volatility on the Tunisian stock market, in accordance with the mixture of distributions hypothesis. Moreover, we show that whatever the frequency of the data used, daily or intraday, the number of transactions is much more significant than the trade size in explaining price volatility and seems to be the main driving factor for the positive volume-volatility relationship. The trade size, despite having a significantly positive effect on volatility for some securities, it has no explanatory power of price changes beyond that of the number of transactions. Overall our results provide an empirical support to the strategic asymmetric information models but do not support the competitive asymmetric information models.

The remainder of this paper is organized as follows. Section 2 presents the methodology employed in this study. The sample and the data are presented in Section 3. Section 4 exposes and discusses the empirical results and the last section concludes.

\section{Methodology}

According to the Mixture of Distribution Hypothesis, trading volume and price volatility are distributed together as a function of information arrival rate which is qualified as mixing variable. In this context, a positive contemporaneous relationship is frequently proven between both variables, a relationship that underlies an instant price adjustment to information. The empirical study of the impact of trading activity on unconditional price volatility of the listed stocks on the Tunisian Stock Exchange follows a three steps approach. First, through analyzing the contemporaneous volume-volatility relationship, then, by testing the relative impacts of the number of transactions and trade size on volatility using initially daily data and secondly intraday data.

\subsection{Contemporaneous Volume-Volatility Relationship}

Previous empirical studies treating the relationship between trading volume and unconditional price volatility measure volatility through the absolute value of returns or the squared returns or even the standard deviation of price fluctuations. As part of our empirical analysis, we only use the absolute value of returns to measure unconditional volatility (Note 2). In order to test the existence of such contemporaneous relationship, we adopt a similar methodology to the one proposed by Lee and Rui (2002) and Mestel, Gurgul, and Majdosz (2003, 2005), which estimates the following regressions, based on the ordinary least squares (OLS) or the Cochrane-Orcutt method (in case of errors autocorrelation):

$$
\begin{aligned}
& \left|R_{i t}\right|=\alpha_{i}+\beta_{1 i} V_{i t}+\beta_{2 i}\left|R_{i t-1}\right|+\varepsilon_{1 t} \\
& V_{i t}=\delta_{i}+\lambda_{1 i}\left|R_{i t}\right|+\lambda_{2 i} V_{i t-1}+\varepsilon_{2 t}
\end{aligned}
$$

Where $\mathrm{R}_{\mathrm{it}}$ and $\mathrm{V}_{\mathrm{it}}$ respectively represent the return and the trading volume of stock (i) in $\mathrm{t}$ (day $\mathrm{t}$ ). $\left|R_{i t}\right|$ is a measure of unconditional price volatility. For each stock (i), the daily return is calculated as follows: $R_{i t}=\ln \left(\frac{P_{i t}}{P_{i t-1}}\right) . \mathrm{P}_{\mathrm{it}}$ is the closing price of the stock (i) in t. The significance of the coefficients $\beta_{1 i}$ and $\lambda_{1 i}$ would indicate the evidence of a contemporaneous relationship between the unconditional volatility and trading volume. The introduction of $\left|R_{i t-1}\right|$ in the equation (2) is based on the hypothesis stating that returns are frequently affected by their relatively close past (Jones, Kaul, \& Lipson, 1994; Chan \& Fong, 2000). The coefficient $\lambda_{2 i}$ measures the autocorrelation degree of trading volume. 
Trading volume is measured by the number of traded shares. Returns are calculated from closing price and are adjusted to stock splits.

\subsection{Number of Transactions, Trade Size and Volatility: An Analysis with Daily Data}

After testing the contemporaneous relationship between trading volume and price volatility for all of our sampled shares, as a second step, we will analyze the relative contributions of the number of transactions and the average trade size in the explanation of the volume-volatility relationship. Thus, we follow the methodology used by Huang and Masulis (2003). Therefore, under the ordinary least squares (OLS) or the Cochrane-Orcutt method (in case of errors autocorrelation) we will estimate the following model:

$$
\begin{gathered}
V O L_{i t}=\alpha_{i}+\beta_{i} A V_{i t}+\gamma_{i} N_{i t}+\varepsilon_{i t} \\
V O L_{i t}=\left|R_{i t}\right| \\
A V_{i t}=\frac{Q_{i t}}{N_{i t}}
\end{gathered}
$$

Where $\mathrm{N}_{\mathrm{it}}$ and $\mathrm{AV}_{\text {it }}$ respectively represent the number of transactions and the average trading size of the stock (i) during the trading session $t$. $V_{i t} l_{i t}$ represents a price volatility measure (absolute value of return). $R_{i t}$, is the return of the stock (i) in t. For each stock (i), the daily return is calculated as follows: $R_{i t}=\ln \left(\frac{P_{i t}}{P_{i t-1}}\right)$. Q $\mathrm{Q}_{\mathrm{it}}$ represents the number of traded shares during day t. Coefficients $\beta_{i}$ and $\gamma_{i}$ respectively measure the relative impact of the average trade size and number of transactions on unconditional price volatility and consequently their relative contribution to the explanation of the volume-volatility relationship.

\subsection{Number of Transactions, Trade Size and Volatility: An Analysis with Intraday Data}

Several empirical studies suppose that the temporal aggregation of the intraday transactions in daily amounts could smooth the trade size variability and therefore reduce its information content and its significance and thus call for the use of intraday data in the analyze of the relative impact of the number of transactions and trade size on price volatility. In this context, Huang and Masulis (2003) show that the use of intraday data strengthens the explanatory power of trade size which is becoming significant in the explanation of volatility. Based on this suggestion, we refer to intraday data with a timestamp to the second in order to reanalyze the relative contributions of the number of transactions and the average trade size to the explanation of the volume-volatility relationship.

According to Huang and Masulis (2003) and Louhichi (2011), each trading session (trade day) of the considered study period is divided into time intervals of 30 minutes each. This division allows us to better identify the intraday variations of the different variables. For each 30 minutes interval, we calculate the return, the number of traded shares (trading volume), the number of transactions and the average trade size for each share of our sample.

In order de reanalyze the relative contributions of the number of transactions and trade size in the explanation of the origin of volume-volatility relationship; we estimate the model of Huang and Masulis (2003) using intraday data with time intervals of 30 minutes, related to the studied variables. Thus, model (3) mentioned above takes the following form:

$$
\begin{gathered}
V O L_{i, j, t}=\alpha_{i}+\beta_{i} A V_{i, j, t}+\gamma_{i} N_{i, j, t}+\varepsilon_{i, j, t} \\
V O L_{i, j, t}=\left|R_{i, j, t}\right| \\
A V_{i, j, t}=\frac{Q_{i, j, t}}{N_{i, j, t}}
\end{gathered}
$$

Where $N_{i, j, t}$ and $A V_{i, j, t}$, respectively represent the number of transactions and the average trade size of the stock 
(i) associated with the interval ( $\mathrm{j}$ ) of 30 minutes of the trading session $\mathrm{t}$. $\mathrm{Vol}_{\mathrm{i}, \mathrm{j}, \mathrm{t}}$ represent a measure of price volatility (The absolute value of return). $R_{i, j, t}$, is the return of the stock (i) associated with the time interval (j) of the trade session t. For each stock, the intraday return is calculated from closing prices $P_{i, j, t}$ as follows: $R_{i, j, t}=\ln \left(\frac{P_{i, j, t}}{P_{i, j, t-1}}\right) \cdot P_{i, j, t}$ is the closing price of the stock (i) at the end of each interval (j) of 30 minutes of the trade session t. $Q_{i, j, t}$ represents the number of stocks (i) traded during the interval (j) of the day t. Coefficients $\beta_{i}$ and $\gamma_{i}$ respectively measure the relative impacts of the average trade size and the number of transactions on the unconditional volatility and therefore their relative contributions to the volume-volatility relationship.

Before estimating the coefficients of these different models we first proceed to a preliminary analysis of the studied series. The first study concerns the stationarity of the studied series through implementing unit-root tests of both Augmented Dickey-Fuller (ADF) and Phillips-Peron (PP). After checking the stationarity of the series, we test the presence of a potential multicollinearity problem via Pearson test related to the significance of correlation coefficients between the explanatory variables of the same model mainly the coefficients of the variables from models (3) and (4). Once these preliminary tests are carried out, we use OLS method to estimate the coefficients of the considered models. However, in order to apply OLS method as an adequate estimation method, we should first test the presence of possible errors autocorrelation. If errors are not correlated, OLS method will provide consistent estimators with minimal variances and therefore we will apply it in our estimations. In case of errors autocorrelation, we will refer to Cochrane-Orcutt method.

\section{Sample and Data}

The empirical study of the relationship between the trading activity and price volatility is based on daily and intraday data related to a sample of the 43 most active and dynamic individual stocks listed on the Tunis Stock Exchange (TSE) running from January 2, 2008 to June 29, 2012 for the daily analysis and from 03 October 2011 to 28 September 2012 for the intraday analysis. Table 1 presents the list of these 43 companies specifying for each company its activity sector, the horizon of data period and the number of observations. For the shares that were traded for the first time after 02 January 2008, daily data are considered from the trade date (the first trade day) until 29 June 2012.

Table 1. List companies of the sample of study

\begin{tabular}{llcccc}
\hline \multirow{2}{*}{ Company Name } & \multicolumn{2}{c}{ Industry } & \multicolumn{2}{c}{ Daily data Period } & \multicolumn{2}{c}{ Observations } \\
\cline { 3 - 6 } & & Start & End & Daily & Intraday \\
\hline Amen Bank & Finance & $02 / 01 / 2008$ & $29 / 06 / 2012$ & 1081 & 1399 \\
BT & Finance & $02 / 01 / 2008$ & $29 / 06 / 2012$ & 1099 & 1539 \\
BIAT & Finance & $02 / 01 / 2008$ & $29 / 06 / 2012$ & 1091 & 1003 \\
ATTIJARI Bank & Finance & $02 / 01 / 2008$ & $29 / 06 / 2012$ & 1109 & 1405 \\
BH & Finance & $02 / 01 / 2008$ & $29 / 06 / 2012$ & 1076 & 749 \\
UIB & Finance & $02 / 01 / 2008$ & $29 / 06 / 2012$ & 1100 & 1309 \\
STB & Finance & $02 / 01 / 2008$ & $29 / 06 / 2012$ & 1102 & 1050 \\
ATB & Finance & $02 / 01 / 2008$ & $29 / 06 / 2012$ & 1105 & 1402 \\
BNA & Finance & $02 / 01 / 2008$ & $29 / 06 / 2012$ & 1100 & 1172 \\
Tunisie Leasing & Finance & $02 / 01 / 2008$ & $29 / 06 / 2012$ & 1089 & 773 \\
Arab Tunisian Lease (ATL) & Finance & $02 / 01 / 2008$ & $29 / 06 / 2012$ & 1095 & 917 \\
CIL & Finance & $02 / 01 / 2008$ & $29 / 06 / 2012$ & 1086 & 988 \\
El WIFACK Leasing & Finance & $02 / 01 / 2008$ & $29 / 06 / 2012$ & 1070 & 780 \\
\hline
\end{tabular}




\begin{tabular}{|c|c|c|c|c|c|}
\hline Modern Leasing & Finance & $03 / 12 / 2010$ & $29 / 06 / 2012$ & 380 & 1053 \\
\hline SPIDIT SICAF & Finance & $02 / 01 / 2008$ & $28 / 06 / 2012$ & 1055 & 737 \\
\hline TUNINVEST SICAR & Finance & $02 / 01 / 2008$ & $29 / 06 / 2012$ & 887 & 450 \\
\hline STAR & Finance & $02 / 01 / 2008$ & $29 / 06 / 2012$ & 1087 & 1128 \\
\hline ASSURANCES SALIM (SALIM) & Finance & $05 / 04 / 2010$ & $29 / 06 / 2012$ & 493 & 441 \\
\hline TUNIS RE & Finance & $19 / 05 / 2010$ & $29 / 06 / 2012$ & 511 & 1469 \\
\hline SOTETEL & Telecommunications & $02 / 01 / 2008$ & $29 / 06 / 2012$ & 1091 & 1508 \\
\hline Magasin Genral (SMG) & Consumer Services & $02 / 01 / 2008$ & $29 / 06 / 2012$ & 1036 & 884 \\
\hline MONOPRIX & Consumer Services & $02 / 01 / 2008$ & $29 / 06 / 2012$ & 1095 & 1476 \\
\hline ARTES & Consumer Services & $08 / 04 / 2008$ & $29 / 06 / 2012$ & 1039 & 1413 \\
\hline ENNAKL Automobiles (ENNAKL) & Consumer Services & $16 / 07 / 2010$ & $29 / 06 / 2012$ & 471 & 1637 \\
\hline SFBT & Consumer Services & $02 / 01 / 2008$ & $29 / 06 / 2012$ & 1107 & 1401 \\
\hline TUNISAIR & Consumer Services & $02 / 01 / 2008$ & $29 / 06 / 2012$ & 1099 & 1483 \\
\hline ADWYA & Health & $02 / 01 / 2008$ & $29 / 06 / 2012$ & 1105 & 1538 \\
\hline ASSAD & Consumer Goods & $02 / 01 / 2008$ & $29 / 06 / 2012$ & 1105 & 1144 \\
\hline GIF-FILTER & Consumer Goods & 03/01/2008 & $29 / 06 / 2012$ & 1050 & 1545 \\
\hline SOPAT & Consumer Goods & $02 / 01 / 2008$ & $29 / 06 / 2012$ & 968 & 1492 \\
\hline POULINA Group Holding (PGH) & Consumer Goods & $20 / 08 / 2008$ & $29 / 06 / 2012$ & 946 & 1480 \\
\hline ELECTROSTAR & Consumer Goods & $02 / 01 / 2008$ & $29 / 06 / 2012$ & 1000 & 1035 \\
\hline SOMOCER & Industry & $02 / 01 / 2008$ & $29 / 06 / 2012$ & 1075 & 1595 \\
\hline SIMPAR & Industry & $02 / 01 / 2008$ & $29 / 06 / 2012$ & 981 & 985 \\
\hline SITS & Industry & $02 / 01 / 2008$ & $29 / 06 / 2012$ & 1097 & 1467 \\
\hline ESSOUKNA (SOKNA) & Industry & $02 / 01 / 2008$ & $29 / 06 / 2012$ & 1004 & 1311 \\
\hline Ciments de Bizerte (SCB) & Industry & $21 / 10 / 2009$ & $29 / 06 / 2012$ & 649 & 1015 \\
\hline Carthage CEMENT (CC) & Industry & $23 / 06 / 2010$ & $29 / 06 / 2012$ & 490 & 1784 \\
\hline SIAME & Industry & $02 / 01 / 2008$ & $29 / 06 / 2012$ & 1074 & 1094 \\
\hline SOTUVER & Industry & $02 / 01 / 2008$ & $29 / 06 / 2012$ & 997 & 1516 \\
\hline TPR & Basics Materials & $02 / 01 / 2008$ & $29 / 06 / 2012$ & 1109 & 1588 \\
\hline SOTRAPIL & Oil and Gas & $02 / 01 / 2008$ & $29 / 06 / 2012$ & 1077 & 1195 \\
\hline TELNET HOLDING (TELNET) & Technology & $23 / 05 / 2011$ & $29 / 06 / 2012$ & 280 & 1498 \\
\hline
\end{tabular}

The data on which this empirical study is based are: the closing price, the number of traded shares, the number of transactions, and the average trade size for each share of our sample. These data are either daily data or intraday ones related to 30 minutes intervals established on the basis of high frequency observations with timestamp to the second. All these data are provided by the Tunis Stock Exchange excluding Saturdays, Sundays, public holidays and days when the share is not traded.

\section{Empirical Results}

\subsection{Preliminary Results}

Before empirically studying the contemporaneous volume-volatility relationship and testing the relative contributions of the number of transactions and trade size to the explanation of its origin, we first started with a preliminary analysis of the studied series via the stationarity test, multicollinearity test between the explanatory variables of models (3) and (4), and the errors autocorrelation test (Note 3).

The stationarity of the series $N_{t}, V_{t}, A V_{t}$ and $\left|R_{t}\right|$ are studied via unit-root tests of Augmented Dickey-Fuller (ADF) and Phillips-Peron (PP). The results of this test show the rejection of the unit roots null hypothesis in the daily and intraday considered series, for all shares, which implies the stationarity of all the series and therefore, 
we can regress our models without any problem.

The multicollinearity study is demonstrated with reference to Pearson test related to the significance of the correlation between the exogenous variables of the same model mainly those of models (3) and (4). Based on the obtained results, we notice the absence of multicollinearity problem between the number of transactions $\left(\mathrm{N}_{\mathrm{it}}\right)$ and the trade size $\left(\mathrm{AV}_{\mathrm{it}}\right)$, for all shares, since correlation coefficients between these variables are statistically non significant to usual thresholds. These results confirm the suggestion of Jones, Kaul and Lipson (1994) who consider that both measures of the trading activity are not often correlated with each other although they are strongly and positively correlated with the trading volume.

Models of type (1), (2), (3) and (4) are often estimated via the ordinary least squared (OLS) method. However, this method will not provide consistent estimators with minimal variance if the errors are autocorrelated. Thus, we have tested the presence of potential errors dependence from the residual analysis via the Durbin Watson (DW) test (models 3 and 4) and Durbin test for models containing lagged explanatory variables (models 1 and 2).

These tests resulted in the existence of a potential errors autocorrelation of order one (Note 4), for most of shares. Hence, the estimators provided by the OLS method are not with minimal variance. In order to correct this problem, several econometric techniques were proposed in previous empirical analyses. One of the model estimation techniques, in case of errors autocorrelation of order 1, is to correct the autocorrelation coefficient via the application of the Cochrane-orcutt method. Other methods were also proposed in order to estimate such type of models in the presence of errors autocorrelation such as the Generalized Least Squared method (GCM), the instrumental variables method, and the Generalized Method of Moments (GMM). The GMM corrects both the heteroskedasticity effects and the errors autocorrelation and it is often applied to estimate empirical models especially those with lagged explanatory variables such as model (1) and (2). The only difference between the application of these techniques mentioned above and the use of GMM concerns the variance estimation of error terms. But for a high observations number, similarly to our analysis, this difference will not matter. Therefore, applying this technique we can obtain same results based on other techniques even under the existence of lagged explanatory variables.

Thus, during the estimation of the considered models, in our empirical analysis we limited ourselves in our empirical analysis to the application of the OLS method under no errors autocorrelation, and the Cochrane-Orcutt method if the errors are autocorrelated (Note 5).

\subsection{Contemporaneous Volatility-Volume Relationship}

In order to study the contemporaneous relationship between trading volume and unconditional price volatility (measured by the absolute value of returns), we estimated models (1) and (2) presented above using Ordinary Least Squares (OLS) with no errors autocorrelation and Cochrane-Orcutt method in case of potential autocorrelation. The results of coefficients estimation of these models are presented in Tables 2 and 3 below.

Tables 2 and 3 respectively summarize the results of coefficient estimation of model (1) and (2) in order to test the contemporaneous relationship between trading volume and price volatility on the Tunisian stock market. The results of model (1) show that, for 38 shares among 43, coefficients $\beta_{1}$ are positive and statistically significant as shown by the t-statistics, which implies that trading volume has a significant positive impact on price volatility. For other shares, this positive impact of the volume is not significant. Given that price volatility is highly influenced by information flow (Lamoureux \& Lastrapes, 1990; Kalev, Liu, Pham, \& Jarnecic, 2004; Huang \& Wang, 2012; Celik, 2013; ...), the significance of volume impact on volatility could be explained by the information content of trading activity. Indeed, price volatility is a manifestation of the temporal variability of information flow whose volume is a proxy, so that the days including several information would be associated with an important trading volume and thus large price fluctuations, and that the slow information flow could reduce both trade and price movements. 
Table 2. Contemporaneous relationship between trading volume and unconditional price volatility (model 1)

\begin{tabular}{|c|c|c|c|c|c|c|c|}
\hline \multirow{2}{*}{$\begin{array}{l}\text { Stocks } \\
\text { Amen Bank }\end{array}$} & \multicolumn{2}{|c|}{$\alpha$} & \multicolumn{2}{|c|}{$\beta_{1}$} & \multicolumn{2}{|c|}{$\beta_{2}$} & \multirow{2}{*}{$\begin{aligned} \bar{R}^{2} \\
0,095\end{aligned}$} \\
\hline & 0,00498 & $(10,16)^{*}$ & $1,50 \mathrm{E}-07$ & $(5,56)^{*}$ & 0,42351 & $(9,64)^{*}$ & \\
\hline ATB & 0,00369 & $(9,14)^{*}$ & 1,84 E-08 & $(1,89)^{* * *}$ & 0,55614 & $(16,11)^{*}$ & 0,136 \\
\hline ATTIJARI Bank & 0,00520 & $(8,01)^{*}$ & $2,40 \mathrm{E}-10$ & $(0,38)$ & 0,44092 & $(7,13)^{*}$ & 0,191 \\
\hline $\mathrm{BH}$ & 0,00416 & $(9,54)^{*}$ & 3,81 E-08 & $(4,30)^{*}$ & 0,50190 & $(13,11)^{*}$ & 0,121 \\
\hline BIAT & 0,00417 & $(9,83)^{*}$ & 7,12 E-09 & $(1,42)$ & 0,51991 & $(13,29)^{*}$ & 0,138 \\
\hline BNA & 0,00399 & $(9,71)^{*}$ & $6,16 \mathrm{E}-08$ & $(7,86)^{*}$ & 0,51887 & $(15,93)^{*}$ & 0,157 \\
\hline BT & 0,00268 & $(8,33)^{*}$ & 1,33 E-08 & $(2,32)^{* *}$ & 0,63382 & $(21,76)^{*}$ & 0,195 \\
\hline STB & 0,00580 & $(12,28)^{*}$ & 8,35 E-08 & $(8,48)^{*}$ & 0,31079 & $(11,20)^{*}$ & 0,168 \\
\hline UIB & 0,00453 & $(10,25)^{*}$ & $-2,29$ E-09 & $(-0,69)$ & 0,40379 & $(8,01)^{*}$ & 0,054 \\
\hline ATL & 0,00475 & $(8,75)^{*}$ & 5,08 E-08 & $(5,33) *$ & 0,47970 & $(12,99)^{*}$ & 0,087 \\
\hline CIL & 0,00574 & $(9,15)^{*}$ & $1,30 \mathrm{E}-07$ & $(3,21)^{*}$ & 0,43100 & $(9,09) *$ & 0,088 \\
\hline Modern Leasing & 0,00756 & $(8,78)^{*}$ & 1,78 E-07 & $(4,17)^{*}$ & 0,30802 & $(6,32)^{*}$ & 0,159 \\
\hline SPIDIT SICAF & 0,00808 & $(17,22)^{*}$ & 4,60 E-09 & $(0,66)$ & 0,18393 & $(6,06)^{*}$ & 0,032 \\
\hline Tunisie Leasing & 0,00493 & $(10,25)^{*}$ & $6,81 \mathrm{E}-08$ & $(3,84)^{*}$ & 0,48670 & $(12,64)^{*}$ & 0,085 \\
\hline Tuninvest SICAR & 0,00756 & $(9,37)^{*}$ & 8,73 E-07 & $(7,57)^{*}$ & 0,36153 & $(7,57)^{*}$ & 0,084 \\
\hline El WIFACK Leasing & 0,00384 & $(9,02)^{*}$ & $1,50 \mathrm{E}-07$ & $(6,53)^{*}$ & 0,45888 & $(11,01)^{*}$ & 0,124 \\
\hline SALIM & 0,00485 & $(6,97)^{*}$ & 1,55 E-07 & $(4,29)^{*}$ & 0,45680 & $(7,94)^{*}$ & 0,124 \\
\hline STAR & 0,00548 & $(8,73)^{*}$ & $9,54 \mathrm{E}-07$ & $(10,05)^{*}$ & 0,38232 & $(8,43)^{*}$ & 0,201 \\
\hline TUNIS RE & 0,00505 & $(6,18)^{*}$ & 1,19 E-07 & $(6,46)^{*}$ & 0,44497 & $(8,24)^{*}$ & 0,141 \\
\hline SOTETEL & 0,01036 & $(15,64)^{*}$ & 2,03 E-07 & $(8,88) *$ & 0,22840 & $(7,93) *$ & 0,143 \\
\hline ARTES & 0,00619 & $(13,72)^{*}$ & 8,44 E-08 & $(8,01)^{*}$ & 0,22841 & $(7,68)^{*}$ & 0,131 \\
\hline ENNAKL & 0,00288 & $(4,88)^{*}$ & 3,98 E-08 & $(6,98)^{*}$ & 0,63967 & $(16,06)^{*}$ & 0,355 \\
\hline MONOPRIX & 0,00759 & $(11,72)^{*}$ & 4,92 E-07 & $(5,97)^{*}$ & 0,14171 & $(4,78)^{*}$ & 0,057 \\
\hline SFBT & 0,00409 & $(9,38)^{*}$ & 3,07 E-08 & $(3,38)^{*}$ & 0,41946 & $(9,30)^{*}$ & 0,072 \\
\hline SMG & 0,00544 & $(9,11)^{*}$ & 4,61 E-08 & $(0,95)$ & 0,53771 & $(12,99)^{*}$ & 0,184 \\
\hline TUNISAIR & 0,00566 & $(10,54)^{*}$ & $1,10 \mathrm{E}-08$ & $(6,80)^{*}$ & 0,50821 & $(14,37)^{*}$ & 0,154 \\
\hline ADWYA & 0,00260 & $(6,60)^{*}$ & $1,22 \mathrm{E}-07$ & $(14,32)^{*}$ & 0,50126 & $(16,49)^{*}$ & 0,298 \\
\hline ASSAD & 0,00343 & $(7,71)^{*}$ & 2,01 E-07 & $(10,39)^{*}$ & 0,47673 & $(13,89)^{*}$ & 0,222 \\
\hline ELECTROSTAR & 0,00796 & $(11,29)^{*}$ & $6,29 \mathrm{E}-07$ & $(11,22)^{*}$ & 0,43856 & $(11,57)^{*}$ & 0,251 \\
\hline GIF & 0,00569 & $(8,14)^{*}$ & 1,46 E-07 & $(12,22)^{*}$ & 0,38421 & $(8,82)^{*}$ & 0,288 \\
\hline PGH & 0,00633 & $(14,34)^{*}$ & 2,63 E-08 & $(2,23)^{* *}$ & 0,30708 & $(9,85)^{*}$ & 0,130 \\
\hline SOPAT & 0,01270 & $(6,01)^{*}$ & $3,65 \mathrm{E}-08$ & $(4,13)^{*}$ & 0,23916 & $(2,09)^{* * *}$ & 0,075 \\
\hline SOMOCER & 0,00599 & $(10,46)^{*}$ & 7,07 E-08 & $(5,71)^{*}$ & 0,59488 & $(20,22)^{*}$ & 0,180 \\
\hline SIMPAR & 0,00676 & $(10,18)^{*}$ & 7,46 E-07 & $(6,34)^{*}$ & 0,42632 & $(10,18)^{*}$ & 0,086 \\
\hline SITS & 0,00733 & $(7,87)^{*}$ & 7,27 E-08 & $(10,14)^{*}$ & 0,24425 & $(3,32)^{*}$ & 0,165 \\
\hline SOKNA & 0,00682 & $(10,57)^{*}$ & 2,40 E-07 & $(7,92)^{*}$ & 0,42306 & $(9,75)^{*}$ & 0,132 \\
\hline $\mathrm{SCB}$ & 0,00251 & $(4,46)^{*}$ & 4,92 E-07 & $(15,16)^{*}$ & 0,47586 & $(12,53)^{*}$ & 0,392 \\
\hline $\mathrm{CC}$ & 0,00314 & $(4,33)^{*}$ & 7,36 E-09 & $(6,93) *$ & 0,55851 & $(12,21)^{*}$ & 0,329 \\
\hline SIAME & 0,00310 & $(7,67)^{*}$ & 3,43 E-08 & $(10,07)^{*}$ & 0,63989 & $(25,12)^{*}$ & 0,298 \\
\hline SOTUVER & 0,00631 & $(9,95)^{*}$ & 2,44 E-08 & $(2,53)^{* *}$ & 0,60464 & $(18,70)^{*}$ & 0,171 \\
\hline TPR & 0,00475 & $(9,27)^{*}$ & $3,11 \mathrm{E}-08$ & $(6,15)^{*}$ & 0,41035 & $(9,63)^{*}$ & 0,084 \\
\hline SOTRAPIL & 0,00755 & $(10,94)^{*}$ & 4,46 E-07 & $(9,56)^{*}$ & 0,38827 & $(9,12)^{*}$ & 0,138 \\
\hline TELNET & 0,00386 & $(5,27)^{*}$ & 1,30 E-07 & $(7,03) *$ & 0,25702 & $(4,53) *$ & 0,253 \\
\hline
\end{tabular}

Note. This table presents the estimation results of the model (1): $\left|R_{i t}\right|=\alpha_{i}+\beta_{1 i} V_{i t}+\beta_{2 i}\left|R_{i t-1}\right|+\varepsilon_{1 t}$, with the OLS or the Cochrane-Orcutt method. $\mathrm{R}_{\mathrm{it}}$ and $\mathrm{V}_{\mathrm{it}}$ are respectively the return and the trading volume of stock (i) in $\mathrm{t}$ (day $\mathrm{t}$ ). The significance of $\beta_{1 i}$ would indicate the impact of trading volume on price volatility. The t-statistics are given in parenthesis.

$*, * *, * * *$ denote significant at the $1 \%, 5 \%$, and $10 \%$ levels, respectively. 
Table 3. Contemporaneous relationship between trading volume and unconditional price volatility (model 2)

\begin{tabular}{|c|c|c|c|c|c|c|c|}
\hline \multirow{2}{*}{$\begin{array}{l}\text { Stocks } \\
\text { Amen Bank }\end{array}$} & \multicolumn{2}{|c|}{$\delta$} & \multicolumn{2}{|c|}{$\lambda_{1}$} & \multicolumn{2}{|l|}{$\lambda_{2}$} & \multirow{2}{*}{$\begin{aligned} \bar{R}^{2} \\
0,044\end{aligned}$} \\
\hline & 1193,99 & $(2,69)^{*}$ & 173781,8 & $(5,77)^{*}$ & 0,25722 & $(4,04)^{*}$ & \\
\hline ATB & 5670,11 & $(5,56)^{*}$ & 176106,1 & $(2,48)^{* *}$ & 0,39555 & $(9,46)^{*}$ & 0,028 \\
\hline ATTIJARI Bank & 25056,06 & $(1,30)$ & 225384,6 & $(0,17)$ & $-0,00171$ & $(-0,05)$ & 0,001 \\
\hline $\mathrm{BH}$ & 2372,93 & $(2,05)^{* *}$ & 331591,6 & $(4,02)^{*}$ & 0,41259 & $(8,92)^{*}$ & 0,072 \\
\hline BIAT & $-865,28$ & $(-0,42)$ & 790874,9 & $(5,08)^{*}$ & 0,23234 & $(3,62)^{*}$ & 0,022 \\
\hline BNA & 298,68 & $(0,29)$ & 518763,2 & $(7,54)^{*}$ & 0,68253 & $(27,68)^{*}$ & 0,341 \\
\hline BT & 7841,28 & $(4,36)^{*}$ & 514563,9 & $(4,22)^{*}$ & 0,29246 & $(5,09)^{*}$ & 0,027 \\
\hline STB & 3185,24 & $(2,74)^{*}$ & 462805 & $(6,54)^{*}$ & 0,55659 & $(16,01)^{*}$ & 0,256 \\
\hline UIB & 5691,04 & $(2,24)^{* *}$ & 463311,9 & $(2,01)^{* *}$ & 0,40583 & $(9,88)^{*}$ & 0,022 \\
\hline ATL & 6623,58 & $(4,97)^{*}$ & 311924,7 & $(4,37)^{*}$ & 0,50995 & $(14,40)^{*}$ & 0,101 \\
\hline CIL & 2495,40 & $(1,60)$ & 46496,9 & $(2,47)^{* *}$ & 0,23010 & $(0,59)$ & 0,191 \\
\hline Modern Leasing & 763,31 & $(0,87)$ & 167561,9 & $(3,40)^{*}$ & 0,58795 & $(12,07)^{*}$ & 0,330 \\
\hline SPIDIT SICAF & 3815,34 & $(2,26)^{* *}$ & 56106,6 & $(0,46)$ & 0,37065 & $(8,37)^{*}$ & 0,015 \\
\hline Tunisie Leasing & 4367,46 & $(5,95)^{*}$ & 147509,5 & $(3,11)^{*}$ & 0,04960 & $(1,63)$ & 0,012 \\
\hline Tuninvest SICAR & 331,39 & $(2,44)^{* *}$ & 22553,03 & $(3,45)^{*}$ & 0,69319 & $(23,35)^{*}$ & 0,352 \\
\hline El WIFACK Leasing & 1991,12 & $(4,18)^{*}$ & 206868,5 & $(5,90)^{*}$ & 0,19811 & $(6,67)^{*}$ & 0,077 \\
\hline SALIM & $-234,15$ & $(-0,38)$ & 269510,2 & $(6,49)^{*}$ & 0,54232 & $(11,83)^{*}$ & 0,184 \\
\hline STAR & 409,96 & $(2,89)^{*}$ & 59965,4 & $(7,87)^{*}$ & 0,53952 & $(15,15)^{*}$ & 0,313 \\
\hline TUNIS RE & 3948,44 & $(2,91)^{*}$ & 288300,3 & $(3,73)^{*}$ & 0,57859 & $(12,67)^{*}$ & 0,201 \\
\hline SOTETEL & 85,94 & $(0,15)$ & 158981,4 & $(5,89)^{*}$ & 0,74321 & $(33,50)^{*}$ & 0,412 \\
\hline ARTES & 2694,07 & $(2,37)^{* *}$ & 555520 & $(7,55)^{*}$ & 0,51006 & $(18,84)^{*}$ & 0,315 \\
\hline ENNAKL & 5663,36 & $(1,15)$ & 2091099 & $(7,50)^{*}$ & 0,12695 & $(2,77)^{*}$ & 0,153 \\
\hline MONOPRIX & 280,03 & $(1,97)^{* *}$ & 33600,7 & $(4,63)^{*}$ & 0,78833 & $(38,11)^{*}$ & 0,507 \\
\hline SFBT & 7767,08 & $(6,24)^{*}$ & 365476,5 & $(4,17)^{*}$ & 0,30518 & $(5,47)^{*}$ & 0,030 \\
\hline SMG & 160,37 & $(0,55)$ & 76301,08 & $(4,63)^{*}$ & 0,32297 & $(5,59)^{*}$ & 0,044 \\
\hline TUNISAIR & 58,95 & $(0,01)$ & 3701892 & $(7,73)^{*}$ & 0,13549 & $(4,63)^{*}$ & 0,076 \\
\hline ADWYA & 4747,73 & $(4,05)^{*}$ & 903331,6 & $(12,45)^{*}$ & 0,35095 & $(13,24)^{*}$ & 0,306 \\
\hline ASSAD & 1744,81 & $(3,49)^{*}$ & 220766,3 & $(7,02)^{*}$ & 0,64382 & $(23,21)^{*}$ & 0,366 \\
\hline ELECTROSTAR & $-761,43$ & $(-3,14)^{*}$ & 105668,1 & $(8,82)^{*}$ & 0,65011 & $(24,23)^{*}$ & 0,392 \\
\hline GIF & 1576,11 & $(1,42)$ & 329356,4 & $(6,35)^{*}$ & 0,73537 & $(30,75)^{*}$ & 0,583 \\
\hline PGH & 20066,19 & $(1,62)$ & 291051,1 & $(3,39)^{*}$ & 0,01499 & $(0,46)$ & 0,012 \\
\hline SOPAT & 6054,77 & $(2,51)^{* *}$ & 303895,8 & $(3,08)^{*}$ & 0,51111 & $(13,18)^{*}$ & 0,100 \\
\hline SOMOCER & $-1037,61$ & $(-0,08)$ & 354683,2 & $(6,36)^{*}$ & 0,39543 & $(8,49)^{*}$ & 0,106 \\
\hline SIMPAR & 370,78 & $(2,80)^{*}$ & 27177,7 & $(3,98)^{*}$ & 0,48648 & $(11,22)^{*}$ & 0,152 \\
\hline SITS & 5507,94 & $(2,72)^{*}$ & 984373,1 & $(8,68)^{*}$ & 0,38635 & $(14,28)^{*}$ & 0,249 \\
\hline SOKNA & $-24,99$ & $(-0,07)$ & 90376,1 & $(4,28)^{*}$ & 0,71968 & $(29,05)^{*}$ & 0,323 \\
\hline SCB & 3628,09 & $(3,57)^{*}$ & 419276,4 & $(13,05)^{*}$ & $-0,04964$ & $(-0,69)$ & 0,358 \\
\hline $\mathrm{CC}$ & 51806,41 & $(2,28)^{* *}$ & 8408531 & $(6,64)^{*}$ & 0,56278 & $(12,07)^{*}$ & 0,296 \\
\hline SIAME & 3586,45 & $(1,07)$ & 1399076 & $(6,92)^{*}$ & 0,34737 & $(6,52)^{*}$ & 0,128 \\
\hline SOTUVER & 3019,72 & $(1,64)$ & 262985,7 & $(3,25)^{*}$ & 0,28439 & $(9,39)^{*}$ & 0,093 \\
\hline TPR & 11153,96 & $(4,66)^{*}$ & 798864,9 & $(5,54)^{*}$ & 0,45393 & $(10,74)^{*}$ & 0,127 \\
\hline SOTRAPIL & $-21,28$ & $(-0,07)$ & 129234,9 & $(7,99)^{*}$ & 0,41083 & $(9,82)^{*}$ & 0,137 \\
\hline TELNET & 3030,40 & $(1,68)^{* * *}$ & 876412,1 & $(5,76)^{*}$ & 0,48787 & $(7,49)^{*}$ & 0,277 \\
\hline
\end{tabular}

Note. This table presents the estimation results of the model (2): $V_{i t}=\delta_{i}+\lambda_{1 i}\left|R_{i t}\right|+\lambda_{2 i} V_{i t-1}+\varepsilon_{2 t}$, with the OLS method or the Cochrane-Orcutt method. $\mathrm{R}_{\mathrm{it}}$ and $\mathrm{V}_{\mathrm{it}}$ are respectively the return and the trading volume of stock (i) in $\mathrm{t}$ (day $\mathrm{t}$ ). The significance of $\lambda_{1 i}$ would indicate the evidence of the contemporaneous volume-volatility relationship. The t-statistics are given in parenthesis.

$*, * *, * * *$ denote significant at the $1 \%, 5 \%$, and $10 \%$ levels, respectively. 
The non significance of trade volume impact on price volatility of the shares of ATIJARI, BIAT, UIB, SPIDIT-SICAF and SMG could be explained by the inability of this variable to appropriately measure information content of trading activity. This is in line with the findings of Jones, Kaul and Lipson (1994), Gopinath and Krishnamurti (2001), Huang and Masulis (2003), Chan and Fong (2006), Giot, Laurent and Petitjean (2010), Kao and Fung (2012), and Shahzed, Duong, Kalev and Singh (2014) who assume that the number of transactions is more informative than the volume and thus it has a higher explanatory power of price volatility and therefore of the relationship between volatility and trading volume. Thus, through replacing the volume $\left(\mathrm{V}_{\mathrm{t}}\right)$ by the number of transactions $\left(\mathrm{N}_{\mathrm{t}}\right)$ in equation (1) for the considered shares, we notice that coefficients $\beta_{1}$ become all significantly positive as shown in Table 4 . This means that trading activity has always a significantly positive impact on price volatility but it depends on choosing of the best trading activity measure: the measure which provides more information content and therefore plays the role of the best information proxy which highly affects price volatility through trading activity as documented in the microstructure literature.

Table 4. Significance of coefficients $\beta_{1}$ taking into account the number of transactions

\begin{tabular}{|c|c|c|c|c|c|c|}
\hline & \multicolumn{3}{|c|}{$\beta_{1}$ as the coefficient of $V_{t}$} & \multicolumn{3}{|c|}{$\beta_{1}$ as the coefficient of $N_{t}$} \\
\hline & coefficient & t-statistic & $\bar{R}^{2}$ & coefficient & t-statistic & $\bar{R}^{2}$ \\
\hline ATTIJARI & $2,40 \mathrm{E}-10$ & $(0,38)$ & 0,191 & 5,92 E-05 & $(9,28)^{*}$ & 0,270 \\
\hline BIAT & 7,12 E-09 & $(1,42)$ & 0,138 & $6,90 \mathrm{E}-05$ & $(8,67)^{*}$ & 0,198 \\
\hline UIB & $-2,29$ E-09 & $(-0,69)$ & 0,054 & $2,31 \mathrm{E}-05$ & $(4,55)^{*}$ & 0,072 \\
\hline SPIDIT-SICAF & 4,60 E-09 & $(0,66)$ & 0,032 & 0,000225 & $(10,56)^{*}$ & 0,125 \\
\hline SMG & $4,61 \mathrm{E}-08$ & $(0,95)$ & 0,184 & 0,000108 & $(8,72)^{*}$ & 0,247 \\
\hline
\end{tabular}

Note. This table presents estimation results, using the OLS method or Cochrane-Orcutt method, of model (1) through replacing the trading volume by the number of transactions as follows: $\left|R_{i t}\right|=\alpha_{i}+\beta_{1 i} N_{i t}+\beta_{2 i}\left|R_{i t-1}\right|+\varepsilon_{1 t}$. The significance of $\beta_{1 i}$ would indicate the impact of number of transactions on price volatility. The t-statistics are given in parenthesis.

* denotes significant at $1 \%$ level.

Estimation results of model (2) show that, for 41 shares among 43 , coefficients $\lambda_{1}$ are significantly positive which indicates that the current price volatility could be useful to predict the variation magnitude the trading volume. The joint significance of the coefficients $\beta_{1}$ and $\lambda_{1}$ confirm the strong positive contemporaneous relationship between trading volume and unconditional price volatility. These results support works of Lee and Rui (2002), Mestel, Gurgul, and Majdosz (2003, 2005), Kumar, Singh, and Pandey (2009), Huang and Wang (2012), Chuang, Liu, and Susmel (2012), Celik (2013), Davidsson (2014)... This contemporaneous relationship is mainly due to the joint dependence of volume and volatility to the information arrival rate as predicted by the Mixture of Distribution Hypothesis (MDH) assuming that the dissemination of the new information is contemporaneous and that the instant reaction of the different actors regarding its arrival on the market implies a positive contemporaneous relationship between volume and volatility where the current value of trading volume could explain the current price volatility. Indeed, on one hand, price volatility is strongly influenced even driven by information and on the other hand, trading activity provides considerable information content and acts as information flow proxy as suggested by previous literature, which could generate a strong positive contemporaneous volume-volatility relationship. The joint dependence of volume and volatility to information flow confirms our hypothesis H1.

Overall, obtained results demonstrate the existence of a highly significant relationship between trading volume and price volatility. However, this first empirical study does not allow us to identify the volume component leading this relationship. In particular, since trading volume can be divided in number of transactions and trade size, it is questionable if this relationship is driven by either one of the variables or both components?

\subsection{Number of Transactions, Trade Size and Volatility: An Analysis with Daily Data}

Based on hypothesis of the strategic asymmetric information models stating that informed investors can hide their trades by fragmenting them into small and medium-sized transactions which gives the number of transaction an important information content and seen the theoretical ambiguity of the role of trade size while explaining price change, we examined the relative roles of the number of transactions and the trade size in the volume-volatility relationship. For that, we referred to the methodology of Huang and Masulis (2003) estimating model (3) by the Ordinary Least Squares (OLS) method or the method of Cochrane-Orcutt (in case of errors autocorrelation). The results of these estimations are presented in Table 5. 
Table 5. Relative effects of the number of transactions and the trade size on price volatility: An analysis with daily data

\begin{tabular}{|c|c|c|c|c|c|c|c|}
\hline \multirow{2}{*}{$\begin{array}{l}\text { Stocks } \\
\text { Amen Bank }\end{array}$} & \multicolumn{2}{|c|}{$\alpha$} & \multicolumn{2}{|c|}{$\boldsymbol{\beta}$} & \multicolumn{2}{|c|}{$\gamma$} & \multirow{2}{*}{$\begin{aligned} \overline{\boldsymbol{R}}^{\mathbf{2}} \\
0,187\end{aligned}$} \\
\hline & 0,00601 & $(13,22)^{*}$ & $1,03 \mathrm{E}-06$ & $(1,48)$ & 0,00012 & $(13,10)^{*}$ & \\
\hline ATB & 0,00664 & $(9,59)^{*}$ & 5,38 E-08 & $(0,51)$ & 7,49 E-05 & $(4,95)^{*}$ & 0,151 \\
\hline ATTIJARI Bank & 0,00495 & $(7,48)^{*}$ & 1,06 E-09 & $(0,10)$ & 8,70 E-05 & $(9,79)^{*}$ & 0,255 \\
\hline $\mathrm{BH}$ & 000549 & $(10,70)^{*}$ & $-2,39 \mathrm{E}-08$ & $(-0,35)$ & 0,00015 & $(11,62)^{*}$ & 0,192 \\
\hline BIAT & 0,00609 & $(11,54)^{*}$ & 1,37 E-08 & $(0,07)$ & 8,64 E-05 & $(8,92)^{*}$ & 0,183 \\
\hline BNA & 0,00688 & $(13,08)^{*}$ & $-5,20$ E-07 & $(-0,94)$ & 9,18 E-05 & $(13,86)^{*}$ & 0,190 \\
\hline BT & 0,00459 & $(7,30)^{*}$ & $-9,70$ E-08 & $(-0,55)$ & 5,82 E-05 & $(9,09)^{*}$ & 0,207 \\
\hline STB & 0,00672 & $(10,88)^{*}$ & 3,19 E-08 & $(0,03)$ & 8,28 E-05 & $(11,89)^{*}$ & 0,213 \\
\hline UIB & 0,00609 & $(13,27)^{*}$ & $-4,02$ E-07 & $(-1,35)$ & 3,62 E-05 & $(5,40)^{*}$ & 0,074 \\
\hline ATL & 0,00767 & $(10,32)^{*}$ & 3,83 E-07 & $(0,42)$ & 8,31 E-05 & $(7,62)^{*}$ & 0,088 \\
\hline CIL & 0,00611 & $(8,95)^{*}$ & $-3,46$ E-07 & $(-0,49)$ & 0,00023 & $(10,43)^{*}$ & 0,155 \\
\hline Modern Leasing & 0,01081 & $(9,14)^{*}$ & 8,53 E-06 & $(1,43)$ & 1,39 E-05 & $(3,12)^{*}$ & 0,152 \\
\hline SPIDIT SICAF & 0,00674 & $(12,77)^{*}$ & $-9,58 \mathrm{E}-07$ & $(-2,35)^{* *}$ & 0,00024 & $(10,73)^{*}$ & 0,127 \\
\hline Tunisie Leasing & 0,00672 & $(12,63)^{*}$ & $-2,86 \mathrm{E}-07$ & $(-0,88)$ & 0,00012 & $(10,52)^{*}$ & 0,141 \\
\hline Tuninvest SICAR & 0,01114 & $(13,49)^{*}$ & 3,75 E-06 & $(1,29)$ & 0,00024 & $(7,53)^{*}$ & 0,070 \\
\hline El WIFACK Leasing & 0,00502 & $(10,21)^{*}$ & $3,80 \mathrm{E}-07$ & $(1,51)$ & 0,00020 & $(10,85)^{*}$ & 0,173 \\
\hline SALIM & 0,00863 & $(10,96)^{*}$ & $-2,55 \mathrm{E}-07$ & $(-0,24)$ & $6,24 \mathrm{E}-05$ & $(5,53)^{*}$ & 0,120 \\
\hline STAR & 0,00771 & $(10,82)^{*}$ & 1,77 E-06 & $(0,27)$ & 0,00011 & $(11,78)^{*}$ & 0,204 \\
\hline TUNIS RE & 0,00832 & $(8,64)^{*}$ & $-1,55 \mathrm{E}-06$ & $(-0,84)$ & 6,33 E-05 & $(8,15)^{*}$ & 0,152 \\
\hline SOTETEL & 0,01125 & $(11,41)^{*}$ & $5,21 \mathrm{E}-06$ & $(0,77)$ & $7,10 \mathrm{E}-05$ & $(9,34)^{*}$ & 0,159 \\
\hline ARTES & 0,00709 & $(13,34)^{*}$ & 9,87 E-08 & $(0,18)$ & $5,17 \mathrm{E}-05$ & $(10,01)^{*}$ & 0,158 \\
\hline ENNAKL & 0,00718 & $(7,41)^{*}$ & 3,02 E-06 & $(2,01)^{* *}$ & 2,33 E-05 & $(12,11)^{*}$ & 0,432 \\
\hline MONOPRIX & 0,00738 & $(8,18)^{*}$ & $-1,29 \mathrm{E}-05$ & $(-1,40)$ & 0,00012 & $(8,91)^{*}$ & 0,090 \\
\hline SFBT & 0,00444 & $(9,22)^{*}$ & $-1,68 \mathrm{E}-07$ & $(-1,36)$ & 9,93 E-05 & $(10,48)^{*}$ & 0,136 \\
\hline SMG & 0,00917 & $(13,19)^{*}$ & 1,57 E-06 & $(0,71)$ & 0,00013 & $(8,51)^{*}$ & 0,229 \\
\hline TUNISAIR & 0,00607 & $(9,37)^{*}$ & 1,17 E-06 & $(3,82)^{*}$ & $9,31 \mathrm{E}-05$ & $(13,74)^{*}$ & 0,234 \\
\hline ADWYA & 0,00416 & $(5,66)^{*}$ & 5,49 E-06 & $(2,98)^{*}$ & 7,72 E-05 & $(12,39)^{*}$ & 0,259 \\
\hline ASSAD & 0,00466 & $(7,48)^{*}$ & 4,67 E-07 & $(0,67)$ & 0,00015 & $(15,21)^{*}$ & 0,239 \\
\hline ELECTROSTAR & 0,01388 & $(19,28)^{*}$ & 6,93 E-07 & $(0,37)$ & 0,00020 & $(13,92)^{*}$ & 0,247 \\
\hline GIF & 0,00660 & $(5,61)^{*}$ & $1,20 \mathrm{E}-05$ & $(3,93)^{*}$ & 6,94 E-05 & $(10,59)^{*}$ & 0,236 \\
\hline PGH & 0,00830 & $(16,21)^{*}$ & 2,90 E-08 & $(1,15)$ & 1,60 E-05 & $(4,77)^{*}$ & 0,121 \\
\hline SOPAT & 0,01479 & $(16,62)^{*}$ & 3,77 E-07 & $(1,21)$ & 5,79 E-05 & $(5,72)^{*}$ & 0,091 \\
\hline SOMOCER & 0,01106 & $(15,39)^{*}$ & 8,49 E-09 & $(0,19)$ & 6,29 E-05 & $(12,47)^{*}$ & 0,200 \\
\hline SIMPAR & 0,01122 & $(18,31)^{*}$ & $-9,42$ E-07 & $(-0,57)$ & 0,00016 & $(8,33)^{*}$ & 0,089 \\
\hline SITS & 0,00774 & $(11,79)^{*}$ & 2,30 E-06 & $(2,85)^{*}$ & 7,66 E-05 & $(10,47)^{*}$ & 0,180 \\
\hline SOKNA & 0,01119 & $(18,97)^{*}$ & 1,86 E-06 & $(1,75)^{* * *}$ & 0,00012 & $(7,89)^{*}$ & 0,117 \\
\hline $\mathrm{SCB}$ & 0,00571 & $(6,30)^{*}$ & $-3,26$ E-06 & $(-1,26)$ & 0,00024 & $(17,84)^{*}$ & 0,402 \\
\hline $\mathrm{CC}$ & 0,00374 & $(2,88)^{*}$ & $6,28 \mathrm{E}-08$ & $(0,13)$ & 3,22 E-05 & $(10,47)^{*}$ & 0,373 \\
\hline SIAME & 0,00831 & $(8,91)^{*}$ & 3,60 E-08 & $(0,37)$ & 8,63 E-05 & $(7,89)^{*}$ & 0,269 \\
\hline SOTUVER & 0,01283 & $(16,50)^{*}$ & 3,65 E-07 & $(1,81)^{* * *}$ & $9,21 \mathrm{E}-05$ & $(8,98)^{*}$ & 0,201 \\
\hline TPR & 0,00589 & $(9,36)^{*}$ & $125 \mathrm{E}-07$ & $(0,24)$ & 5,75 E-05 & $(9,18)^{*}$ & 0,103 \\
\hline SOTRAPIL & 0,01053 & $(17,21)^{*}$ & 3,58 E-06 & $(1,56)$ & 0,00015 & $(11,41)^{*}$ & 0,156 \\
\hline TELNET & 0,00420 & $(5,03)^{*}$ & $-1,18$ E-06 & $(-0,82)$ & 5,72 E-05 & $(9,29)^{*}$ & 0,301 \\
\hline
\end{tabular}

Note. This table presents the estimation results of the model (3): $V O L_{i t}=\alpha_{i}+\beta_{i} A V_{i t}+\gamma_{i} N_{i t}+\varepsilon_{i t}$, by the OLS method or the Cochrane-Orcutt method. $\mathrm{N}_{\mathrm{it}}$ and $\mathrm{AV}_{\mathrm{it}}$ respectively represent the number of transactions and the trade size of the stock i in t. Vol ${ }_{\mathrm{it}}$ represent price volatility measure. $\beta_{i}$ and $\gamma_{i}$ measure the relative effects of trade size and number of transactions on price volatility. The t-statistics are given in parenthesis.

$*, * *, * * *$ denote significant at the $1 \%, 5 \%$, and $10 \%$ levels, respectively. 
According to Table 5, we notice that for all shares, coefficients $\gamma_{i}$ are positive and statistically significant which means that the number of transactions has positive significant impact on price volatility as shown by the t-statistics. The strong significance of these coefficients is justified by the importance of the information content of the number of transactions leading to price change. This is in line with the findings of Jones, Kaul, and Lipson (1994), Jiang and Kryzanowiski (1998), Gopinath and Krishnamurti (2001), Huang and Masulis (2003), Giot, Laurent, and Petitjean (2010), Kao and Fung (2012), and Shahzed, Duong, Kalev, and Singh (2014) stating that the number of transactions is the most appropriate measure of trading activity due to communicated information on the market and therefore it is the best proxy for the information flow that is at the origin of all price changes.

The estimation results of model (3) also show that coefficients $\beta_{i}$ are significantly positive only for seven among 43 selected shares indicating that in general, trade size does not have a significant positive impact on price volatility. This implies that in average, trade size does not have additional information content, beyond that of the number of transactions, and that any information related to the trading activity is almost entirely included in the number of transactions that significantly influence the price volatility of all shares. Thus, the positivity of the volume-volatility relationship simply reflects the positive relationship between the number of transactions and volatility.

Overall, these results show that the number of transactions is much more significant than trade size in the explanation of the price volatility and seems to be the dominant factor that drives the positive volume-volatility relationship, and that despite having a significantly positive impact on volatility for the case of some shares, trade size do not provide an explanatory power of price changes beyond the one provided by the number of transactions. Thus, these results highlight the camouflage strategy adopted by informed Tunisian investors that chose to fragment their trading activity in several smaller and medium-sized transactions in order to not reveal their informational advantages which leads them to multiply their interventions on the stock market so that the number of transactions would become high and therefore provides information content that could significantly affect price volatility.

This finding is in accordance with the hypothesis of the strategic models of Kyle (1985), Admati and Pfleiderer (1988), Foster and Viswanathan (1996), Chordia and Subrahmanyam (2004), and Cho (2007) stating that an informed investor prefers to conceal its trading activities through fragmenting them and progressively treating them in order to hide its privileged identity. Therefore, the interpretation of the different actors of such behavior as informative could generate large price fluctuations. In this context, trade size communicates a trivial information compared to the one disseminated by the number of transactions. The high significance level of number of transactions' impact on price volatility reflects the strategic camouflage behavior of the informed Tunisian investors. This confirms our hypothesis $\mathrm{H} 2$ and challenges our hypothesis $\mathrm{H} 3$ predicting that, similarly to the theoretical predictions of the competitive models (Easley \& O'Hara, 1987; Holthausen \& Verrecchia, 1990; Back \& Baruch, 2007; Ozsoylev \& Takayama, 2010), informed investors prefer to trade large amounts of shares to enjoy their private information, which can provide important information content to the trade size and thus leads to the significance of its positive relationship with price volatility. Therefore, our results support the hypothesis of the strategic asymmetric information models and bring into question the hypothesis of competitive asymmetric information models.

Our empirical results are consistent with Jones, Kaul, and Lipson (1994), Gopinath and Krishnamurti (2001), Huang and Masulis (2003), Chan and Fong (2006), Giot, Laurent, and Petitjean (2010), Kao and Fung (2012) and Shahzed, Duong, Kalev, and Singh (2014) who show that volume-volatility positive relationship simply reflects the positive relationship between the price volatility and the number of transactions. Conversely, Chan and Fong (2000) find that both the number of transactions and the trade size play significant roles in this relationship.

\subsection{Number of Transactions, Trade Size and Volatility: An Intraday Analysis}

Using daily data, we confirmed the hypothesis of the strategic models showing that the number of transactions is the dominant factor leading the volume-volatility positive relationship. However, some studies falling within the same context, suggested that the temporal aggregation of intraday transactions in daily amounts could smooth trade size variability and thus reduce its information content and its significance, and therefore call for the use of intraday data while analyzing the relative effects of the number of transactions and the trade size on price volatility. Based on this suggestion, we used intraday data with timestamp to the second to reanalyze the relative contributions of the number of transactions and the average trade size while explaining the origin of the positive volatility-volume relationship by estimating the model (4) Results of these estimations are presented in Table 6 . 
Table 6. Relative effects of the number of transactions and the trade size on price volatility: An intraday analysis

\begin{tabular}{|c|c|c|c|c|c|c|c|}
\hline \multirow{2}{*}{$\begin{array}{l}\text { Stocks } \\
\text { Amen Bank }\end{array}$} & \multicolumn{2}{|c|}{$\alpha$} & \multicolumn{2}{|l|}{$\beta$} & \multicolumn{2}{|c|}{$\gamma$} & \multirow{2}{*}{$\frac{\bar{R}^{2}}{0,025}$} \\
\hline & 0,004467 & $(6,51)^{*}$ & 4,32 E-06 & $(4,96)^{*}$ & 0,000101 & $(1,76)^{* * *}$ & \\
\hline ATB & 0,003747 & $(15,15)^{*}$ & $-1,97$ E-07 & $(-0,66)$ & 0,000111 & $(5,39)^{*}$ & 0,099 \\
\hline ATTIJARI Bank & 0,003761 & $(13,95)^{*}$ & $-1,36$ E-06 & $(-1,57)$ & 0,000105 & $(4,36)^{*}$ & 0,114 \\
\hline $\mathrm{BH}$ & 0,006364 & $(10,74)^{*}$ & $1,51 \mathrm{E}-07$ & $(1,39)$ & 0,000212 & $(3,61)^{*}$ & 0,143 \\
\hline BIAT & 0,004292 & $(13,01)^{*}$ & $3,61 \mathrm{E}-07$ & $(7,73)^{*}$ & 0,000154 & $(3,74)^{*}$ & 0,146 \\
\hline BNA & 0,004733 & $(13,84)^{*}$ & $-8,84$ E-09 & $(-0,10)$ & 0,000189 & $(5,98)^{*}$ & 0,081 \\
\hline BT & 0,001934 & $(12,85)^{*}$ & $-7,93$ E-09 & $(-0,08)$ & $6,25 \mathrm{E}-05$ & $(8,01)^{*}$ & 0,099 \\
\hline STB & 0,005970 & $(13,39)^{*}$ & $-1,04$ E-06 & $(-1,19)$ & 0,000298 & $(6,10)^{*}$ & 0,070 \\
\hline UIB & 0,003695 & $(14,19)^{*}$ & 1,21 E-07 & $(0,19)$ & 0,000126 & $(5,01)^{*}$ & 0,037 \\
\hline ATL & 0,007723 & $(16,73)^{*}$ & $-3,52$ E-06 & $(-3,81)^{*}$ & 0,000145 & $(5,08)^{*}$ & 0,074 \\
\hline $\mathrm{CIL}$ & 0,005696 & $(14,84)^{*}$ & $-3,00 \mathrm{E}-06$ & $(-2,04) * *$ & 0,000104 & $(1,98)^{* *}$ & 0,040 \\
\hline Modern Leasing & 0,008485 & $(19,82)^{*}$ & $-4,81$ E-06 & $(-2,70)^{*}$ & 0,000126 & $(2,70)^{*}$ & 0,039 \\
\hline SPIDIT SICAF & 0,005739 & $(10,55)^{*}$ & $-3,81 \mathrm{E}-07$ & $(-1,22)$ & 0,000223 & $(2,94)^{*}$ & 0,107 \\
\hline Tunisie Leasing & 0,007389 & $(14,49)^{*}$ & 1,45 E-07 & $(0,79)$ & 3,32 E-05 & $(0,33)$ & 0,049 \\
\hline Tuninvest SICAR & 0,011536 & $(12,49)^{*}$ & $-5,62 \mathrm{E}-06$ & $(-1,41)$ & 4,90 E-05 & $(0,48)$ & 0,012 \\
\hline El WIFACK Leasing & 0,010979 & $(14,04)^{*}$ & $1,57 \mathrm{E}-06$ & $(0,33)$ & 5,99 E-05 & $(0,61)$ & 0,013 \\
\hline SALIM & 0,012473 & $(13,44)^{*}$ & $-1,75$ E-06 & $(-1,78)^{* * *}$ & 0,000111 & $(0,80)$ & 0,057 \\
\hline STAR & 0,005023 & $(14,67)^{*}$ & $-0,96$ E-06 & $(-0,74)$ & $8,62 \mathrm{E}-05$ & $(3,14)^{*}$ & 0,085 \\
\hline TUNIS RE & 0,004210 & $(15,99)^{*}$ & 9,22 E-07 & $(1,83)^{* * *}$ & 0,000151 & $(8,15)^{*}$ & 0,079 \\
\hline SOTETEL & 0,005408 & $(17,05)^{*}$ & 9,77 E-07 & $(1,47)$ & 0,000132 & $(10,25)^{*}$ & 0,098 \\
\hline ARTES & 0,002047 & $(8,92)^{*}$ & 2,58 E-09 & $(0,08)$ & 0,000244 & $(14,65)^{*}$ & 0,143 \\
\hline ENNAKL & 0,002574 & $(15,80)^{*}$ & $-2,00 \mathrm{E}-10$ & $(-0,004)$ & 0,000116 & $(22,12)^{*}$ & 0,246 \\
\hline MONOPRIX & 0,003980 & $(13,39)^{*}$ & $-8,23 \mathrm{E}-07$ & $(-1,01)$ & 0,000161 & $(9,83)^{*}$ & 0,074 \\
\hline SFBT & 0,002808 & $(11,22)^{*}$ & 1,35 E-09 & $(0,02)$ & 0,000160 & $(8,56)^{*}$ & 0,092 \\
\hline SMG & 0,004903 & $(9,25)^{*}$ & $1,24 \mathrm{E}-05$ & $(7,18)^{*}$ & 0,000389 & $(10,56)^{*}$ & 0,234 \\
\hline TUNISAIR & 0,004582 & $(16,36)^{*}$ & $1,46 \mathrm{E}-07$ & $(0,89)$ & 0,000154 & $(13,85)^{*}$ & 0,154 \\
\hline ADWYA & 0,004059 & $(12,59)^{*}$ & $-9,90$ E-07 & $(-1,19)$ & 0,000109 & $(10,44)^{*}$ & 0,071 \\
\hline ASSAD & 0,003880 & $(12,95)^{*}$ & $1,11 \mathrm{E}-06$ & $(11,05)^{*}$ & 0,000101 & $(2,65)^{*}$ & 0,210 \\
\hline ELECTROSTAR & 0,005489 & $(6,97)^{*}$ & $1,58 \mathrm{E}-05$ & $(3,89)^{*}$ & 0,000310 & $(18,83)^{*}$ & 0,209 \\
\hline GIF & 0,003259 & $(7,45)^{*}$ & 3,61 E-06 & $(2,59)^{*}$ & 0,000122 & $(16,19)^{*}$ & 0,221 \\
\hline PGH & 0,004158 & $(17,15)^{*}$ & $4,18 \mathrm{E}-07$ & $(6,04)^{*}$ & 6,92 E-05 & $(6,93)^{*}$ & 0,126 \\
\hline SOPAT & 0,005789 & $(18,31)^{*}$ & $-1,71$ E-07 & $(-0,63)$ & 0,000113 & $(10,94)^{*}$ & 0,123 \\
\hline SOMOCER & 0,004996 & $(12,76)^{*}$ & 3,03 E-08 & $(2,77)^{*}$ & 0,000102 & $(15,64)^{*}$ & 0,187 \\
\hline SIMPAR & 0,006185 & $(15,22)^{*}$ & $-1,92$ E-07 & $(-0,64)$ & 0,000192 & $(4,39)^{*}$ & 0,032 \\
\hline SITS & 0,005020 & $(15,78)^{*}$ & $-5,09 \mathrm{E}-07$ & $(-1,24)$ & 0,000116 & $(7,94)^{*}$ & 0,087 \\
\hline SOKNA & 0,003958 & $(10,26)^{*}$ & $-1,22$ E-06 & $(-0,98)$ & 0,000303 & $(10,39)^{*}$ & 0,079 \\
\hline SCB & 0,004950 & $(12,03)^{*}$ & $-1,55$ E-06 & $(-2,04)^{* *}$ & 0,000338 & $(7,26)^{*}$ & 0,109 \\
\hline $\mathrm{CC}$ & 0,001659 & $(11,22)^{*}$ & 4,87 E-07 & $(5,78)^{*}$ & 4,88 E-05 & $(16,41)^{*}$ & 0,218 \\
\hline SIAME & 0,006395 & $(12,01)^{*}$ & 9,90 E-07 & $(1,18)$ & 8,28 E-05 & $(1,51)$ & 0,037 \\
\hline SOTUVER & 0,003954 & $(10,36)^{*}$ & $-1,04 \mathrm{E}-06$ & $(-1,12)$ & 0,000166 & $(7,17)^{*}$ & 0,041 \\
\hline TPR & 0,003422 & $(16,92)^{*}$ & $-3,04 \mathrm{E}-07$ & $(-1,36)$ & 9,05 E-05 & $(7,99)^{*}$ & 0,058 \\
\hline SOTRAPIL & 0,005351 & $(13,88)^{*}$ & 1,15 E-06 & $(0,72)$ & 0,000285 & $(13,56)^{*}$ & 0,154 \\
\hline TELNET & 0,003557 & $(16,67)^{*}$ & 6,22 E-07 & $(5,83)^{*}$ & 0,000127 & $(11,03)^{*}$ & 0,129 \\
\hline
\end{tabular}

Note. This table presents estimation results of the model (4): $V O L_{i, j, t}=\alpha_{i}+\beta_{i} A V_{i, j, t}+\gamma_{i} N_{i, j, t}+\varepsilon_{i, j, t}$, by the OLS method or the Cochrane-Orcutt method. $\mathrm{N}_{\mathrm{i}, \mathrm{j}, \mathrm{t}}$ and $A \mathrm{~V}_{\mathrm{i}, \mathrm{j}, \mathrm{t}}$, respectively represent the number of transactions and trade size of stock (i) in the interval (j) of 30 minutes of the trade day t. $\beta_{i}$ and $\gamma_{i}$ measure the relative effects of trade size and number of transactions on volatility. The t-statistics are given in parenthesis.

$*, * *, * * *$ denote significant at the $1 \%, 5 \%$, and $10 \%$ levels, respectively. 
Estimation results of model (4) based on intraday data show that the coefficient number of transactions is positive for all shares and statistically significant for most of them (38 from 43 shares). However, trade size coefficient is only positive for 21 shares and is only statistically significant for 11 of them. These results imply that the number of transactions remains a variable that has a positive significantly impact on price volatility no matter the frequency of used data; daily or intraday. Conversely, trade size remains in general not significant and does not provide an explanatory power of price volatility beyond that the number of transactions, despite that there is a slight improve of its significance level regarding the explanation of price volatility as shown by coefficient $\beta_{i}$ (that is significant for 7 shares using daily data and for 11 shares using intraday data). Moreover, trade size coefficient is negative for 22 shares and statistically significant for 5 among them which imply that, in general, our results confirm well the theoretical ambiguity of the role played by trade size in the explanation of price changes. Thus, the number of transactions appears to be the dominant factor that drives the positive contemporaneous volume-volatility relationship no matter the frequency of used data; daily or intraday.

The results that we have obtained using intraday data are in general consistent with those obtained in the analysis using daily data implying that temporal aggregation of intraday data in daily amounts did not smooth the trade size variability and therefore did not reduce its information content and its significance. These results contradict the suggestion of Huang and Masulis (2003) who show that the use of intraday data strengthens the explanatory power of the trade size which is becoming significant in the explanation of volatility.

Overall, our results based on intraday data empirically support the hypothesis of strategic asymmetric information models of Kyle (1985), Admati and Pfleiderer (1988), Foster and Viswanathan (1996), Chordia and Subrahmanyam (2004) and Cho (2007), but are in contradiction with the hypothesis of competitive asymmetric information models of Easley and O'Hara (1987), Holthausen and Verrecchia (1990), Back and Baruch (2007), and Ozsoylev and Takayama (2010).

\section{Conclusion}

This paper empirically studies the relationship between trading volume and unconditional price volatility in order to empirically support either the hypothesis of strategic asymmetric information models or the hypothesis of competitive asymmetric information models. For that, we followed a three-step approach. First, through analysing the contemporaneous volume-volatility relationship. Then, through testing the relative impacts of the number of transactions and the trade size on price volatility and therefore test their relative contributions to the explanation of the origin of this relationship using, first, data with daily frequency and, second, intraday data. Our empirical tests are applied to daily and intraday data related to the 43 most active and dynamic traded stocks on the Tunisian stock market running from January 2, 2008 to June 29, 2012 for the daily analysis and from 03 October 2011 to 28 September 2012 for the intraday analysis.

The results show the existence of a strong positive contemporaneous volume-volatility relationship. This contemporaneous relationship is mainly due to the joint dependence of volume and volatility to the information arrival rate as predicted by the Mixture of Distribution Hypothesis (MDH) assuming that the new information dissemination is contemporaneous and that the instant reaction of the different actors regarding its arrival on the market implies a positive contemporaneous relationship between volume and volatility were the current value of trading volume could explain the current price volatility. Our results also show that whatever the frequency of used data, daily or intraday, the number of transaction is more significant than trade size in the explanation of the volatility due to its information content and appears to be the dominant factor that drives the positive volume-volatility relationship. Despite having a positive significant impact on price volatility of some shares, trade size has no explanatory power of price volatility beyond that the number of transactions. The positivity of the volume-volatility relationship simply reflects the positive relationship between volatility and the number of transactions.

According to the hypothesis of strategic asymmetric information models, our empirical results indicate that the informed Tunisian investors adopt strategic camouflage behaviour through fragmenting their trades and progressively treating them in order to not reveal their informational advantages, which leads them to multiply their interventions on the stock market so that their number of transactions becomes high and thus provides information content that could significantly affect price volatility. On the other hand, our results challenge the hypothesis of competitive asymmetric information models predicting that informed investors prefer to trade large amounts of shares to enjoy their private information which can provide information content to trade size and therefore leading to the significance of its positive relationship with price volatility.

\section{References}

Admati A., \& Pfleiderer, P. (1988). A theory of intraday patterns: Volume and price variability. Review of 
Financial Studies, 1, 3-40. http://dx.doi.org/10.1093/rfs/1.1.3

Alsubaie, A., \& Najand, M. (2009). Trading volume, time-varying conditional volatility, and asymmetric volatility spillover in the Saudi stock market. Journal of Multinational Financial Management, 19, 139-159. http://dx.doi.org/10.1016/j.mulfin.2008.09.002

Andersen, T. G. (1996). Return volatility and trading volume: An information flow interpretation of stochastic volatility. Journal of Finance, 51, 169-204. http://dx.doi.org/10.2307/2329306

Andersen, T. G., Bollerslev, T., Diebold, F. X., \& Ebens, H. (2001). The distribution of realized stock return volatility. Journal of Financial Economics, 61, 43-76. http://dx.doi.org/10.1016/S0304-405X(01)00055-1

Back, K., \& Baruch, S. (2007). Working orders in limit-order markets and floor exchanges. Journal of Finance, 61, 1589-1621. http://dx.doi.org/10.1111/j.1540-6261.2007.01252.x

Barclay, M. J., \& Warner, J. B. (1993). Stealth trading and volatility. Journal of Financial Economics, 34, 281-305. http://dx.doi.org/10.1016/0304-405X(93)90029-B

Bollerslev, T., \& Jubinski, D. (1999). Equity trading volume and volatility: Latent information arrivals and common long-run dependencies. Journal of Business and Economic Statistics, 17, 9-21. http://dx.doi.org/10.1080/07350015.1999.10524793

Celik, S. (2013). New evidence on the relation between trading volume and volatility. Business and Economic Research, 3(1), 176-186. http://dx.doi.org/10.5296/ber.v3i1.3222

Chan, C. C., \& Fong, W. M. (2006). Realized volatility and transactions. Journal of Banking \& Finance, 30 , 2063-2085. http://dx.doi.org/10.1016/j.jbankfin.2005.05.021

Chan, F., \& Fong, W. M. (2000). Trade size, order imbalance, and the volatility-volume relation. Journal of Financial Economics, 57(2), 247-273. http://dx.doi.org/10.1016/S0304-405X(00)00057-X

Cho, J. W. (2007). Earnings announcements, private information, and strategic informed trading. Journal of Financial Intermediation, 16, 117-149. http://dx.doi.org/10.1016/j.jfi.2006.10.001

Chordia, T., \& Subrahmanyam, A. (2004). Order imbalance and individual stock returns: Theory and evidence. Journal of Financial Economics, 72, 485-518. http://dx.doi.org/10.1016/S0304-405X(03)00175-2

Chuang, W. I., Liu, H. H., \& Susmel, R. (2012). The bivariate GARCH approach to investigating the relation between stock returns, trading volume, and return volatility. Global Finance Journal, 23(1), 1-15. http://dx.doi.org/10.1016/j.gfj.2012.01.001

Clark, P. K. (1973). A subordinated stochastic process model with finite variance for speculative prices. Econometrica, 41, 135-155. http://dx.doi.org/10.2307/1913889

Copeland, T. E. (1976). A model of Asset trading under the assumption of sequential information arrival. Journal of Finance, 31, 1149-1168. http://dx.doi.org/10.2307/2326280

Darrat, A. F., Rahman, S., \& Zhong, M. (2003). Intraday trading volume and return volatility of the DJIA stocks: A note. Journal of Banking and Finance, 27, 2035-2043. http://dx.doi.org/10.1016/S0378-4266(02)00321-7

Davidsson, M. (2014). Volume, volatility and momentum in financial markets. International Research Journal of Applied Finance, 5(3), 211-223.

Easley, D., \& O'Hara, M. (1987). Price, trade size, and information in securities markets. Journal of Financial Economics, 19, 69-90. http://dx.doi.org/10.1016/0304-405X(87)90029-8

Epps, T. W., \& Epps, M. L. (1976). The stochastic dependence of security price changes and transaction volumes: Implications for the mixture-of-distributions hypothesis. Econometrica, 44, 305-321. http://dx.doi.org/10.2307/1912726

Foster, F. D., \& Viswanathan, S. (1996). Strategic trading when agents forecast the forecast of others. The Journal of Finance, 51(4), 1437-1478. http://dx.doi.org/10.2307/2329400

Giot, P., Laurent, S., \& Petitjean, M. (2010). Trading activity, realized volatility and jumps. Journal of Empirical Finance, 17, 168-175. http://dx.doi.org/10.1016/j.jempfin.2009.07.001

Gopinath, S., \& Krishnamurti, C. (2001). Number of transactions and volatility: An empirical study using high-frequency Data from NASDAQ stocks. Journal of Financial Research, 24(2), 205-218. http://dx.doi.org/10.1111/j.1475-6803.2001.tb00765.x

Harris, M., \& Raviv, A. (1993). Differences of opinion make a horse race. Review of Financial Studies, 6, 
473-506. http://dx.doi.org/10.1093/rfs/6.3.473

Holthausen, R. W., \& Verrecchia, R. E. (1990). The effect of informedness and consensus on price and volume behaviour. The Accounting Review, 65, 191-208.

Huang, R. D., \& Masulis, R. W. (2003). Trading activity and stock price volatility: Evidence from the London Stock Exchange. Journal of Empirical Finance, $10(3), \quad 249-269$. http://dx.doi.org/10.1016/S0927-5398(02)00048-8

Huang, Z., \& Wang, T. (2012). The relationship between volatility and trading volume in the Chinese stock market: A volatility decomposition perspective. Annals of Economics and Finance, 13(1), 217-242.

Jennings, R., \& Barry, C. (1983). Information dissemination and portfolio choice. Journal of Financial and Quantitative Analysis, 18, 1-19. http://dx.doi.org/10.2307/2330801

Jennings, R. H., Starks, L., \& Fellingham, J. (1981). An equilibrium model of asset trading with sequential information arrival. Journal of Finance, 36, 143-161. http://dx.doi.org/10.2307/2327469

Jiang, L., \& Kryzanowiski, L. (1998). Trading activity, quoted liquidity, and stock volatility. Multinational Finance Journal, 3, 199-227.

Jones, C. M., Kaul, G., \& Lipson, M. L. (1994). Transactions, volume, and volatility. Review of Financial Studies, 7, 631-651. http://dx.doi.org/10.1093/rfs/7.4.631

Kalev, P., Liu, W. M., Pham, P. K., \& Jarnecic, E. (2004). Public information arrival and volatility of intraday stock returns. Journal of Banking and Finance, 28(6), 1141-1467. http://dx.doi.org/10.1016/S0378-4266(03)00126-2

Kao, E. H., \& Fung, H. G. (2012). Intraday trading activities and volatility in round-the-clock futures markets. International Review of Economics and Finance, 21, 195-209. http://dx.doi.org/10.1016/j.iref.2011.06.003

Karpoff, J. M. (1987). The relation between price changes and trading volume: A survey. Journal of Financial and Quantitative Analysis, 22, 109-126. http://dx.doi.org/10.2307/2330874

Kumar, B., Singh, P., \& Pandey, A. (2009). The dynamic relationship between price and trading volume: Evidence from Indian stock market (pp. 1-53). Indian Institute of Management Ahmedabad Research and Publications W.P. No. 2009-12-04. http://dx.doi.org/10.2139/ssrn.1527562

Kyle, A. (1985). Continuous auctions and insider trading. Econometrica, 53, 1315-1335. http://dx.doi.org/10.2307/1913210

Lamoureux, C. G., \& Lastrapes, W. D. (1990). Heteroskedasticity in stock return data: Volume versus GARCH effects. Journal of Finance, 45, 221-229. http://dx.doi.org/10.2307/2328817

Lee, B. S., \& Rui, M. O. (2002). The dynamic relationship between stock returns and trading volume: Domestic and cross country evidence. Journal of Banking and Finance, 26, 51-78. http://dx.doi.org/10.1016/S0378-4266(00)00173-4

Louhichi, W. (2011). What drives the volume-volatility relationship on Euronext Paris? International Review of Financial Analysis, 20, 200-206.

Mahajan, S., \& Singh, B. (2009). The empirical investigation of relationship between return, volume and volatility dynamics in Indian stock market. Eurasian Journal of Business and Economics, 2(4), 113-137.

Mestel, R., Gurgul, H., \& Majdosz, P. (2003). The empirical relationship between stock returns, return volatility and trading volume on the Austrian stock market (pp. 1-16). Institute of Banking and Finance, University of Graz, Austria.

Mestel, R., Gurgul, H., \& Majdosz, P. (2005). Joint dynamics of prices and trading volume on the Polish stock market. Managing Global Transitions, 3(2), 139-156.

Morse, D. (1980). Asymmetrical information in securities markets and trading volume. Journal of Financial and Quantitative Analysis, 15, 1129-1148. http://dx.doi.org/10.2307/2330176

Ozsoylev, H. N., \& Takayama, S. (2010). Price, trade size, and information revelation in multi-period securities markets. Journal of Financial Markets, 13, 49-76. http://dx.doi.org/10.1016/j.finmar.2009.10.002

Shahzad, H., Duong, H. N., Kalev, P. S., \& Singh, H. (2014). Trading volume, realized volatility and Jumps in the Australian stock. Journal of International Financial Markets, Institutions and Money, 31, 414-430. http://dx.doi.org/10.1016/j.intfin.2014.04.009 
Shalen, C. T. (1993). Volume, volatility, and the dispersion of beliefs. Review of Financial Studies, 6, 405-434. http://dx.doi.org/10.1093/rfs/6.2.405

Tauchen, G. E., \& Pitts, M. (1983). The price variability-volume relationship on speculative markets. Econometrica, 51, 485-505. http://dx.doi.org/10.2307/1912002

\section{Notes}

Note 1. The number of transactions corresponds to the number of times a share is traded during a given period, while the trade size represents the amount of traded shares for each transaction.

Note 2. According to previous studies, the absolute value is the most robust measure of unconditional volatility comparing with the square returns.

Note 3. For brevity, statistics for these tests are not reported here.

Note 4. Since DW test and Durbin test only detect the autocorrelation of order one, we also verified the Breusch-Godfrey test that allows us to test an autocorrelation of an order higher than 1 . We found that the autocorrelation, if it exists, is generally of order one. As part of this research, we only presented the results of DW test and those of Durbin test that appear to provide conclusive estimation results.

Note 5. As verification, we estimated the considered models with the GMM method and we found the same results as when using OLS method since that the number of transaction is sufficiently high for each of our samples shares.

\section{Copyrights}

Copyright for this article is retained by the author(s), with first publication rights granted to the journal.

This is an open-access article distributed under the terms and conditions of the Creative Commons Attribution license (http://creativecommons.org/licenses/by/3.0/). 